\title{
Barefoot running: Between fashion and real way to prevent joint osteo lesions?
}

\author{
Manon Carpentier ${ }^{1}$, Sara Perpiñá Martínez ${ }^{1}$, Alain De Man², \\ Charalampos Pierrakos ${ }^{2}$, Stefaan Isenborgh ${ }^{3}$, David De Bels ${ }^{2}$, Patrick M. Honore ${ }^{2}$, \\ Walid Salem ${ }^{4}$, Sebastien Redant ${ }^{2}$ \\ 'Department of Physiotherapy, Pontifical University of Salamanca, Campus Madrid, Spain; \\ ${ }^{2}$ Intensive Care Department, Brugmann University Hospital, Free University of Brussels French Part (Université \\ Libre de Bruxelles, ULB), Brussels, Belgium; \\ ${ }^{3}$ Orthopedic Surgery Department, Bracops Hospital, Free University of Brussels Flemish Part (Vrij Universiteit \\ van Brussels, VUB), Brussels, Belgium; \\ ${ }^{4}$ Osteopathy Research Unit, Free University of Brussels French Part (Université Libre de Bruxelles, ULB), \\ Brussels, Belgium
}

\section{ABSTRACT}

Background and objectives: Running has gone from a vital necessity for the man to a playful sport. Different rheumatic and orthopedic pathologies have appeared, in front of which the shoe industry has reacted by creating reinforced shoes that are supposed to overcome the induced lesions. Several years later, the trend toward reinforcement has gone toward minimalism, which is the absence of reinforcement, that is, a more natural race. Method: We observed variations of kinetics and kinematics in young, unprofessional, healthy runners during a shoe race and a shoeless race, which is the form of maximum minimalism. We then correlated minimalism variations with the variables of the race and the joint angles. Results: We observed significant difference $(P<0.01)$ in the cycle rate, the cycle length, the step rate, and the angle of attack between running with and without shoes. A small variation of the minimalism index is associated with an increase in knee angle $\left(r^{2}>0.5\right)$. Conversely, a large variation in the minimalism index is related to a decrease in the knee angle $\left(r^{2}>0.5\right)$. The minimalism index has no impact on the angulation of the ankle and hip $\left(r^{2}<0.3\right)$. Conclusion: Slow transition will bring gains in terms of decreasing the length of the stride, which limits the load on the shin. Greater flexibility can be achieved by decreasing the flexion angle of the knee, which decreases the demand for quadriceps muscles and the risk of knee injury with a greater risk of injury at the tibial level.

Address for Correspondence: Dr Sébastien Redant, Intensive Care Department, Brugmann University Hospital, Free University of Brussels French Part (Université Libre de

Bruxelles, ULB), Place van Gehuchten 4, 1020 Laeken Brussels, Brussels, Belgium

E-mail:

Sebastien.redant@chu-brugmann.be

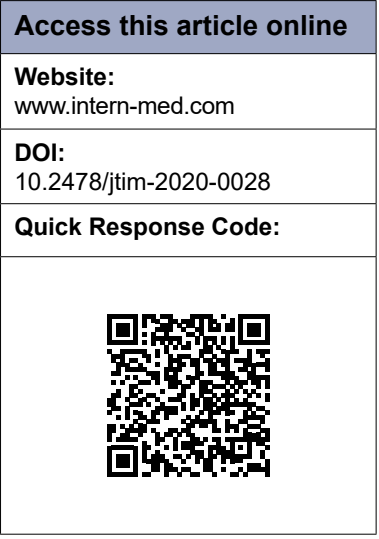

Key words: barefoot running, minimalist index, kinetic, kinematic, rheumatic, orthopedic lesions

\section{INTRODUCTION}

The human being practices the barefoot running for millennia. For the past 30,000 years, people have covered their feet to protect them from the ground that can cause direct wounds. ${ }^{[1]}$ Running, which was originally a natural means of locomotion, has gradually become a recreational sport that has gained popularity in the recent years. This attractiveness for running caused the emergence of new orthopedic lesions with an estimated incidence between $19.4 \%$ and $79 \%{ }^{[2]}$ To respond to this issue, the shoe industry has developed various technologies such as increased cushioning, elevated heel and motion control and stability technologies. ${ }^{[3]}$ The rational was that the support for the race had to be identical to that of the march, that is, to say by a heel foot strike. ${ }^{[4,5]}$ Similarly, for a long time, it was thought that it was necessary to compensate the different types of foot regarding anatomical aspect (pes planus, normal foot, and pes cavus) and mechanical issue (pronating, normal, or supinating foot) as well. ${ }^{[3]}$ All these measures have not succeeded in reducing the rate of lesions with a perverse effect on natural running biomechanics, kinematics, kinetics, and muscle activation pattern.$^{[3]} \mathrm{A}$ "minimalist" shoe, which promotes short strides and midfoot/forefoot strike, has been proposed to limit these injuries. The minimalist 
shoes, featuring a lower profile and a more flexible sole, reduced heel compensation and a lack of motion control technology. There is no need for biomechanical evidence to support the ability to "barefoot" to interact with the natural movement of the inferior member. ${ }^{[1]}$ Several studies show a lower prevalence of foot lesions, ${ }^{[6]}$ an improvement in the economy of stroke, ${ }^{[7]}$ and a decrease in impact forces on the joints. ${ }^{[8]}$

There is, however, a great disparity in the literature regarding the beneficial effect of barefoot running. One hypothesis advanced on this disparity was the lack of uniformity when defining the minimalist shoe. In order to overcome this problem, Esculier et al developed, following a consensus of 42 international experts, the concept of minimalism index expressed in percent. Characteristics taken into account in this index were weight, flexibility, heel to toe drop, stack height, and motion control/stability devices. Zero percent is a maximalist shoes and $100 \%$ is barefoot. The same authors provided recommendations on the transition from traditional footwear to minimalist footwear. These recommendations are based on this minimalist index by proposing to increase the minimalism index by $10 \%$ every month. ${ }^{[3]}$

All authors emphasized the lack of studies concerning changes in race biomechanics correlated with the difference in the degree of "minimalism" between shoes previously used and those tested. ${ }^{[8-10]}$

We propose to measure the impact of acute minimal index variation on the biomechanics of stroke and discuss the potential risks of orthopedic injury caused by these variations (Table 1$)$.

\section{MATERIAL AND METHOD}

\section{Subjects}

Participants were aged 18 years or more. All subjects had to be a regular runner with a maximum distance of $10 \mathrm{~km}$ per session, minimum 1 race session per week. Runners with a history of pathology of the lower limb or spine (traumatic, neurological, and/or rheumatic), with injury or had surgery of the lower limb within 6 months of the start of the experiment, or with against medical indications to the practice of sport or running were excluded.

\section{Experimental protocol}

The subjects do their shopping on a treadmill (brand Powerjog $\left({ }^{\circledR}\right)$ with a mark of joint anatomical landmarks on the skin of participants and undergarments. A slope of $1 \%$, corresponding to flat land, was chosen arbitrarily. Each participant will have to complete three races of $5 \mathrm{~min}$ punctuated by 3 min of passive recovery.

- Race 1: Warm-up: The participant runs his or her first 5-min run at his or her own pace with his or her own shoes to determine the speed that corresponds to his or her usual jogging pace. The speed is determined by the first run using the Borg scale or "effort perception measure." The Borg score should be between a low effort $(2 / 10)$ and moderate $(3 / 10)$ and could not exceed a difficult effort $(5 / 10)$. The speed was chosen to correspond to the usual training speed of the runner.

- Race 2: 5-min race with own shoes at the speed determined during the race 1 .

- Race 3:5-min run without shoes at the speed determined during race 1 .

\section{Variables measured}

- Anthropometric data (sex, age, height, and weight) will be requested before the session. The weekly distance traveled, the minimalist index of the shoe (in percentage), and the weight of the shoe were included.

- Spatiotemporal variables: race cycle (interval of time and space between two successive identical positions, one cycle corresponds to two steps, or successive strides; $\mathrm{cm}$ and sec), step length $(\mathrm{cm})$, stride length $(\mathrm{cm})$, step rate (step/min), and ground contact time (sec)

- Foot-ground interaction: first at the heel, mid-plantar, or on the forefoot.

- Kinematic variables: foot separation in the frontal plane $(\mathrm{cm})$, flexo-extension angles of the lower hip level, knee, and ankle (degrees). Everything is measured during the support phase only.

Collection of biomechanical data is made using GoPro ${ }^{\circledR}$ Hero 5 (GoPro Inc., USA) video surveys in sagittal plane and

\begin{tabular}{lll}
\hline Table 1: Type of injury according to type of footwear (adapted from Murphy et $\left.a l^{[11]}\right)$ \\
\hline Injury type & Barefoot running & Shod running \\
& Forefoot strike & Heel foot strike \\
\hline Patellofemoral pain syndrome & Lower risk & Higher risk \\
Tibial stress syndrome & Possible lower risk & Possible higher risk \\
Plantar fasciitis & Possible higher risk & Inconclusive \\
Metatarsal stress fracture & Higher risk & Lower risk \\
Puncture wounds/infection & Higher risk & Lower risk \\
\hline
\end{tabular}


posterior frontal plane. Biomechanical analysis is performed using the Kinovea ${ }^{\circledR}$ program (Kinovea.org, France).

\section{Statistical analysis}

The results were collected and prepared manually on an excel spreadsheet, and statistical analysis was carried out using the program Prism 6, GraphPad (GraphPad Software, La Jolla, California, USA). A Kolmogorov-Smirnov test allowed us to evaluate the parametric and non-parametric data. For the parametric data, we used a Student t-test to compare the 2 subpopulations. For non-parametric data, a Wilcoxon test was used. Patients were grouped according to the minimalist index variation concentration between their shoes and barefoot, and each group was stratified into quintiles. Linear and nonlinear regression models were estimated to look at the trend in kinetic and kinematic variable. Statistical significance was defined as $P<0.05$.

\section{RESULTS}

We included 26 participants aged $21.7 \pm 2.7$ years. They were all students of a school of kinesitherapy in Brussels and regularly practiced running with an average running distance of $22.4 \pm 18.70 \mathrm{~km} /$ wk. Their anthropometric characteristics are fairly homogeneous with a small standard deviation for age, weight, and height (Table 2). However, they had a great variability in the minimalist index of their shoes (minimum, 4\%; maximum, 62\%; median, 20\%).

When we compare the measurements made during the race with shoes with those made during the race without shoes, there is a significant difference $(P<0.01)$ in the cycle rate, the cycle length, the step rate, and angle of attack. During the race with shoes, we also observe a more frequent heel strike $(22 / 26)$, which decreases by half $(11+26)$ in favor of a midfoot or a forefoot strike during the race without shoes. The runner who was initially in midfoot or in forefoot strike stayed with the same strike (Table 3). The runners who had a forefoot strike with their shoes were the most trained, that is, with the highest weekly training distance $(50,70$, and $80 \mathrm{~km} / \mathrm{wk})$.

A slight decrease in the minimalism index is associated with a greater decrease in the length (Figure 1a) and the duration of the stride (Figure 1b) and a longer contact time (Figure 1c) than a runner, which significantly decreases its index of minimalism $\left(r^{2}>0.5\right)$. The rate of step (Figure 1d) and the angle of attack (Figure 1e) are not correlated with the minimalism index variation $\left(r^{2}<0.5\right)$. Conversely, a large variation in the minimal index results in a smaller decrease in the cycle length, a greater decrease in cycle time, and a shorter contact time.

\section{Table 2: Anthropometric characteristics}

\begin{tabular}{lc}
\hline $\boldsymbol{N}=\mathbf{2 6}$ & Variables \\
\hline Age (years) & $21.70 \pm 2.7$ \\
Weight $(\mathrm{kg})$ & $62.18 \pm 11.62$ \\
Height $(\mathrm{cm})$ & $171.40 \pm 11.69$ \\
Minimalist index $(\%)$ & $20(4-62)$ \\
Weight of shoes $(\mathrm{g})$ & $286.00 \pm 50.38$ \\
Sex ratio & $1 / 2$ \\
Distance of training (km/week) & $22.40 \pm 18.70$ \\
\hline
\end{tabular}

\begin{tabular}{|c|c|c|c|c|}
\hline & Shoes & No shoes & Variation (\%) & $P$ \\
\hline Stride rate $(\mathrm{s})$ & $0.768 \pm 0.040$ & $0.751 \pm 0.040$ & -2.270 & 0.0004 \\
\hline Stride length $(\mathrm{cm})$ & $1.850 \pm 0.390$ & $1.380 \pm 0.290$ & -24.880 & $<0.0001$ \\
\hline step rate $($ step $/ \mathrm{min})$ & $161.400 \pm 8.50$ & $167.700 \pm 9.76$ & +3.91 & $<0.0001$ \\
\hline ground contact time (s) & $0.320 \pm 0.05$ & $0.310 \pm 0.05$ & -0.44 & 0.13 \\
\hline Angle of attack & $9.110 \pm 7.15$ & $1.73 \pm 8.54$ & -36.97 & $<0.0001$ \\
\hline \multicolumn{5}{|l|}{ Attack } \\
\hline Heel & $22 / 26$ & $11 / 26$ & & \\
\hline Mid & $1 / 26$ & $8 / 26$ & & \\
\hline Fore & $3 / 26$ & $7 / 26$ & & \\
\hline
\end{tabular}

Table 4: Variation of joint angle following the type of race (with and without shoes)

\begin{tabular}{|c|c|c|c|c|}
\hline & Shoes & No shoes & Variation (\%) & $P$ \\
\hline Hip & $31.35 \pm 8.9$ & $29.96 \pm 8.43$ & $-3.71 \pm 10.56$ & 0.048 \\
\hline Knee & $11.46 \pm 4.82$ & $12.46 \pm 5.16$ & $12.34 \pm 36.47$ & 0.056 \\
\hline Ankle & $9(-14$ to 20.0$)$ & $4.0(-20$ to 12$)$ & $-46(-322$ to +550$)$ & $<0.0001$ \\
\hline
\end{tabular}




\section{Length of stride}

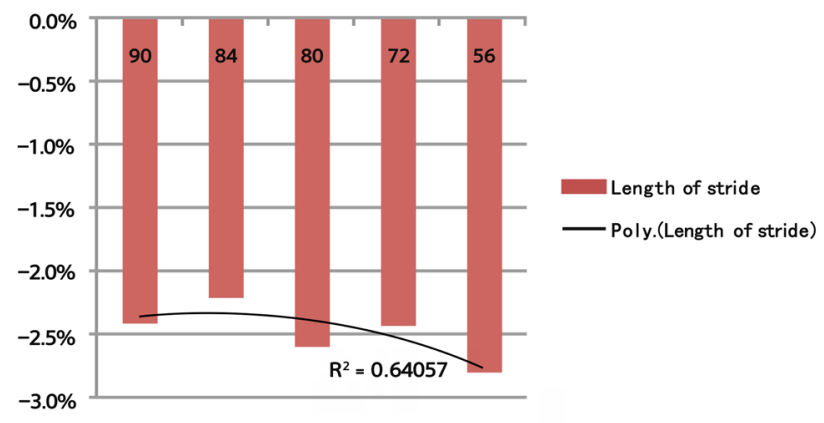

Figure 1a: Correlation between the minimalism index and the length of stride.

\section{Duration of stride}

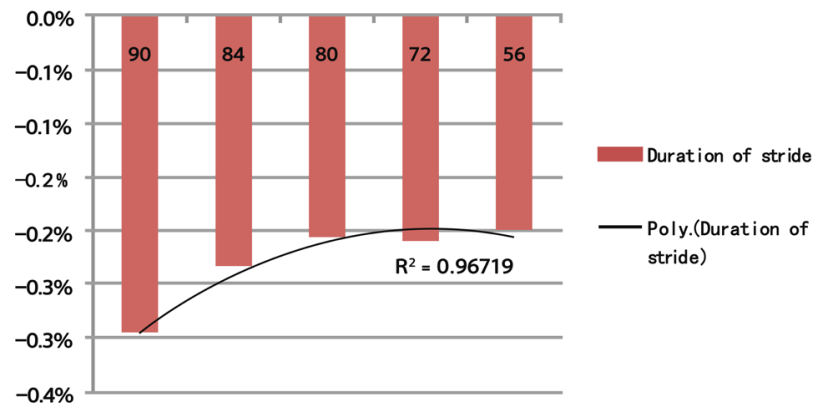

Figure $1 \mathrm{~b}$ : Correlation between the minimalism index and the duration of stride.

When comparing the hip, knee, and ankle angles between running with a shoe and running without a shoe, there is a decrease in hip flexion. The knee has greater flexion without achieving statistical significance $(P=0.056)$ and the ankle shows a decrease in dorsal flexion.

A slight decrease in the minimalism index is associated with an increase in knee angle $\left(r^{2}>0.5\right.$; Figure 2a). Conversely, a large variation in the minimalism index is related to a decrease in the knee angle $\left(r^{2}>0.5\right.$; Figure $\left.2 \mathrm{~b}\right)$. The minimalism index has no impact on the angulation of the ankle and hip $\left(r^{2}<0.3\right.$; Figure 2c).

\section{DISCUSSION}

Several researches have shown that reducing training distances is a way of reducing the risk of injury. The risk of running injuries is related to the distance of the week round. ${ }^{[1-15]}$ Increasing frequency, duration, and intensity of stroke are risk factors for stress fracture ${ }^{[16]}$ Unfortunately, endurance runners are unable or unwilling to reduce their training distance. Attention was then paid to the correction of anatomical variables using reinforced shoes. ${ }^{[1]}$ However, the use of modified shoes did not produce an effect in
Ground contact

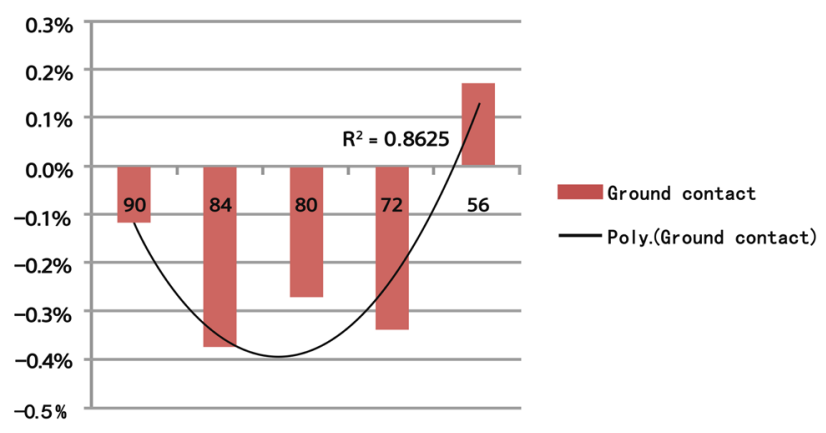

Figure 1c: Correlation between the minimalism index and the ground contact.

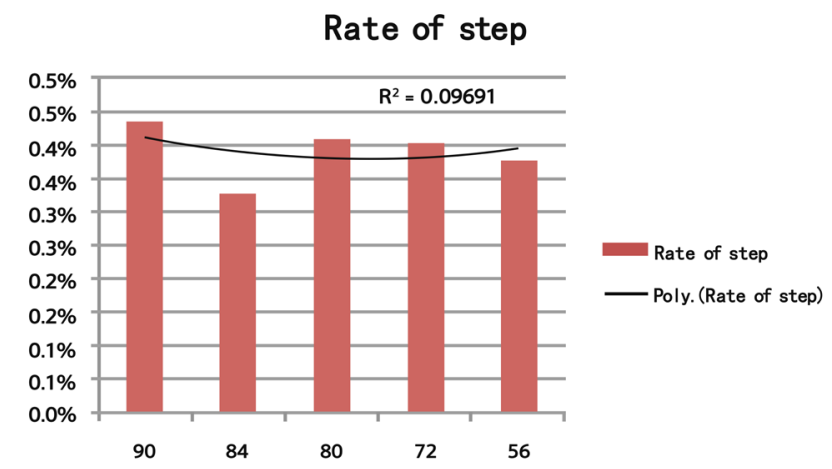

Figure 1d: Correlation between the minimalism index and the rate of step.

\section{Angle of attack}

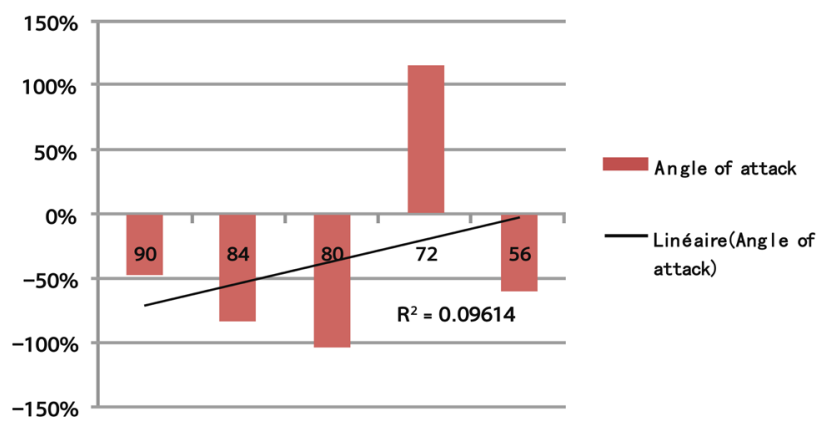

Figure 1e: Correlation between the minimalism index and the angle of attack.

terms of reducing the lesion rate. The prescription of "pronation control, elevated heel" was not based on any evidence demonstrated in the literature with additional added injury. ${ }^{[17]}$ When comparing the prescription of running shoes adapted to the plantar shape versus standard shoes, there is no significant difference in terms of lesion rate. ${ }^{[18,19]}$ Following this, a style of race called "barefoot style" characterized by short stride, light steps, and footwear 


\section{Hip angle variation}

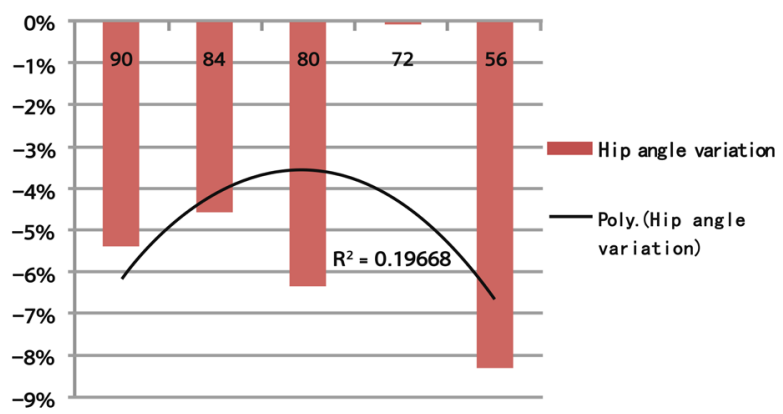

Figure 2a: Correlation between the minimalism index and the hip angle variation.

\section{Knee angle variation}

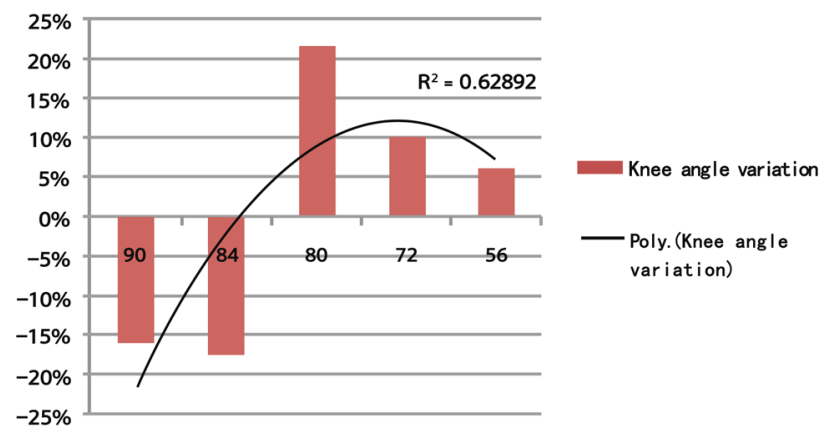

Figure $\mathbf{2 b}$ : Correlation between the minimalism index and the knee angle variation.

Heel angle variation

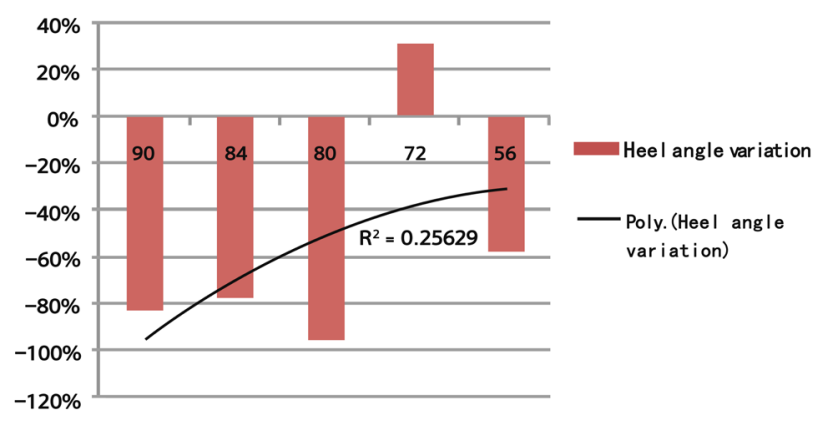

Figure 2c: Correlation between the minimalism index and the knee angle variation.

with minimal protection and maximum flexibility appeared in the runners. ${ }^{[20]}$

We observed a significant decrease in stride length and a significant increase in stride frequency related to the constant speed of the experiment. Shock attenuation has been shown to be correlated with the stride length $(r=0.70)$ more than the stride rate $(r=0.40)$ (Mercer). ${ }^{[21]}$ A $10 \%$ reduction in stride length results in a corresponding decrease in the peak tibial contact force result. However, the concomitant increase in frequency may be accompanied by an increase in metabolic cost and induce an earlier onset of fatigue. ${ }^{[2]}$ The state of muscle fatigue increases bone strains and may be a major factor in the etiology of stress fracture. ${ }^{[23]}$ Under $10 \%$ of variation, it has been shown that there is no change in energy demand related to the concomitant increase in frequency over the same distance. ${ }^{[2]}$ Runners who want to reduce their risk of fracture can do so by reducing $10 \%$ of their length stride. ${ }^{[21]}$

Concerning stride rate, a 10-20\% increase substantially reduces joint loading that provides a beneficial in reducing the risk of developing a running-related injury. ${ }^{[25-28]}$ Beyond $15 \%$ to $20 \%$ increase, a change appears in the foot, which can explain the effect on the discharge of charge that the frequency itself. ${ }^{[2]}$ This is also why we chose to work at constant speed, on the one hand, to stay in the conditions of reality of each participant and then not to induce changes in the pattern of the race by an exaggerated increase in the stride rate that does not match the natural race runners.

We observe a significant difference in the angle of attack. We also observe a more frequent heel strike $(22 / 26)$ in race with shoes that decreases by half $(11+26)$ in favor of a midfoot or a forefoot strike during the race without shoes. It has been shown that runners in a first trial of minimalist footwear who adopted a forefoot strike decreased their loading rate (hashish biomechanics) by $41 \%$. With a midfoot or a forefoot strike, they are able to disperse impact force more efficiently. This could be a result of a dense collection of plantar mechanoreceptors that "feel the ground." ${ }^{[1]} \mathrm{A}$ recent meta-analysis reported a significant relationship between vertical load rates and tibial stress fracture in heel strike runner. ${ }^{[29]}$ Conversely, forefoot runner has a lower vertical load rates. ${ }^{[30]}$

A perverse effect of the strike change is that the runners experiment a series of microtraumas repeated at their metatarsals leading to stress fractures and fractures of the plantar fascia (Table 1).We confirm the preliminary data of Murphy. ${ }^{[1]}$

The main influence of the barefoot on patellofemoral junction (PFJ) is related to smaller knee flexion angle during the stance phase of running, which decreases the demand on the muscles of the quadriceps. It has been measured a $12 \%$ decrease in peak PFJ stress when comparing running barefoot with shod running. ${ }^{[1]}$

There is a decrease in hip flexion. The trunk is projected forward relative to the lower limbs, which facilitates the race. The knee has a greater flexion without reaching the 
statistical significance $(P=0.056)$. More knee flexion allows better shock wave absorption. The ankle presents a decrease in dorsal flexion, which leads to a more forward attack of the typical foot of the minimalist stride.

A slow transition brings a gain in terms of decreasing the length of the stride, which limits the load on the shin. We do not observe a correlation with the frequency or angle of attack that could decrease the pressure on the joints and the load on the tibia. A greater variation of minimalism could bring a benefit by decreasing the flexion angle of the knee, which decreases the demand on quadriceps muscles but with a smaller decrease in cycle length and an increase in the cycle time.

\section{Limitations of the study}

We conducted a study on a 5 -min run, but lesions appeared unpredictably for a period of 1-3 months. In the Salzler study, $86 \%$ of participants reported an injury after an average of 5 weeks (1-19 weeks) after the start of the transition. Metatarsal head plus calf and arch pain were the most common injuries. ${ }^{[32]}$

\section{CONCLUSION}

The benefit of minimalism is marked by a decrease in stride length, an increase in the frequency without exceeding 15\%, and an improvement of the angles. A slow transition brings a gain in terms of decreasing the length of the stride, which limits the load on the shin. Greater variation of minimalism could bring a benefit by decreasing the flexion angle of the knee, which decreases the demand on quadriceps muscles but with a smaller decrease in cycle length and an increase in cycle time.

\section{Conflicts of Interests}

The authors declare to have no competing interest.

\section{REFERENCES}

1. Rixe JA, Gallo RA, Silvis ML. The barefoot debate: can minimalist shoes reduce running-related injuries? Curr Sports Med Rep 2012; 11: 160-5.

2. van Gent RN, Siem D, van Middelkoop M, van Os AG, Bierma-Zeinstra $\mathrm{SM}$, Koes BW. Incidence and determinants of lower extremity running injuries in long distance runners: a systematic review. Br J Sports Med 2007 41: 469-80.

3. Esculier JF, Dubois B, Dionne CE, Leblond J, Roy JS. A consensus definition and rating scale for minimalist shoes. J Foot Ankle Res 2015; 8: 42 .

4. Lieberman DE, Venkadesan M, Werbel WA, Daoud AI, D’Andrea S, Davis IS, et al. Foot strike patterns and collision forces in habitually barefoot versus shod runners. Nature 2010; 463: 531-5.

5. Altman AR, Davis IS. Barefoot running: biomechanics and implications for running injuries. Curr Sports Med Rep 2012; 11: 244-50.

6. D'Août K, Pataky TC, De Clercq D, Aerts P. The effects of habitual foot- wear use: foot shape and function in native barefoot walkers. Footwear Sci 2009; 1: 81-94.

7. Mullen S, Toby EB. Adolescent Runners: The Effect of Training Shoes on Running Kinematics. J Pediatr Orthop 2013; 33: 453-7.

8. Hall JPL, Barton C, Jones PR, Morrissey D. The biomechanical differences between barefoot and shod distance running: a systematic review and preliminary metaanalysis. Sports Med 2013; 43: 1335-53.

9. Bonacci J1, Saunders PU, Hicks A, Rantalainen T, Vicenzino BG, Spratford W. Running in a minimalist and lightweight shoe is not the same as running barefoot: A biomechanical study. Br J Sports Med 2013; 47: 387-92.

10. Hollander K, Argubi-Wollesen A, Reer R, Zech A. Comparison of Minimalist Footwear Strategies for Simulating Barefoot Running: A Randomized Crossover Study. PLoS One, 2015; 10: e0125880.

11. Murphy K, Curry EJ, Matzkin EG. Barefoot running: does it prevent injuries? Sports Med 2013; 43: 1131-8.

12. Macera CA, Pate RR, Powell KE, Jackson KL, Kendrick JS, Craven TE. Predicting lower-extremity injuries among habitual runners. Arch Intern Med 1989; 149: 2565-8.

13. Koplan JP, Powell KE, Sikes RK, Shirley RW, Campbell CC. An epidemiologic study of the benefits and risks of running. JAMA 1982; 248: 3118-21.

14. Marti B, Vader JP, Minder CE, Abelin TH. On the epidemiology of running injuries. Am J Sports Med 1988; 16: 285-94.

15. Brody DM. Running injuries. Clin Symp 1980; 32: 1-36.

16. Harrast MA, Colonno D. Stress fractures in runners. Clin Sports Med 2010; 29: 399-416.

17. Richards CE, Magin PJ, Callister R. Is your prescription of distance running shoes evidence-based? Br J Sports Med 2009; 43: 159-62.

18. Knapik JJ, Trone DW, Tchandja J, Jones BH. Injury-reduction effectiveness of prescribing running shoes on the basis of foot arch height: summary of military investigations. J Orthop Sports Phys Ther 2014; 44: 805-12.

19. Knapik JJ, Trone DW, Swedler DI, Villasenor A, Bullock SH, Schmied $\mathrm{E}$ et al. Injury reduction effectiveness of assigning running shoes based on plantar shape in Marine Corps basic training. Am J Sports Med 2010; 38: 1759-67.

20. Christopher M. Born to Run: A Hidden Tribe, Superathletes, and the Greatest Race the World Has Never Seen. Washington: Vintage Books 2009.

21. Mercer JA, Vance J, Hreljac A, Hamill J. Relationship between shock attenuation and stride length during running at different velocities. Eur J Appl Physiol 2002; 87: 403-8.

22. Hobara H, Sato T, Sakaguchi M, Sato T, Nakazawa K. Step frequency and lower extremity loading during running. Int J Sports Med 2012; 33: 310-3.

23. Milgrom C, Radeva-Petrova DR, Finestone A, Nyska M, Mendelson S, Benjuya $\mathrm{N}$, et al. The effect of muscle fatigue on in vivo tibial strains. J Biomech 2007; 40: 845-50.

24. Hamill J, Gruber AH. Is changing footstrike pattern beneficial to runners? J Sport Health Sci 2017; 6: 146-53.

25. Derrick TR, Hamill J, Caldwell G. Energy absorption of impacts during running at various stride lengths. Med Sci Sports Exerc 1998; 30: 128-35.

26. Edwards WB, Taylor D, Rudolphi TJ, Gillette JC, Derrick TR. Effects of stride length and running mileage on a probabilistic stress fracture model. Med Sci Sports Exerc 2009; 41: 2177-84.

27. Hamill J, Derrick TR, Holt KG. Shock attenuation and stride frequency during running. Hum Mov Sci 1995; 14: 45-60.

28. Heiderscheit B, Chumanov ES, Michalski MP, Wille CM, Ryan MB . Effects of step rate manipulation on joint mechanics during running. MedSci Sports Exerc 2011; 43: 296-302.

29. Hashish R, Samarawickrame SD, Powers CM, Salem GJ. Lower limb dynamics vary in shod runners who acutely transition to barefoot 
Carpentier et al.: Barefoot running and lesion prevention

running. J Biomech 2016; 49: 284-8.

30. Davis IS, Rice HM, Wearing SC. Why forefoot striking in minimal shoes might positively change the course of running injuries. J Sport Health Sci 2017; 6: 154-61.

31. Bonacci J, Vicenzino B, Spratford W, Collins P. Take your shoes off to reduce patellofemoral joint stress during running. Br J Sports Med 2014; 48: 425-8.
32. Salzler MJ, Kirwan HJ, Scarborough DM, Walker JT, Guarino AJ, Berkson EM. Injuries observed in a prospective transition from traditional to minimalist footwear: correlation of high impact transient forces and lower injury severity. Phys Sportsmed 2016; 44: 373-9.

How to cite this article: Carpentier M, Martínez SP, De Man A, Pierrakos C, Isenborgh S, De Bels D, et al. Barefoot running: Between fashion and real way to prevent joint osteo lesions? J Transl Intern Med 